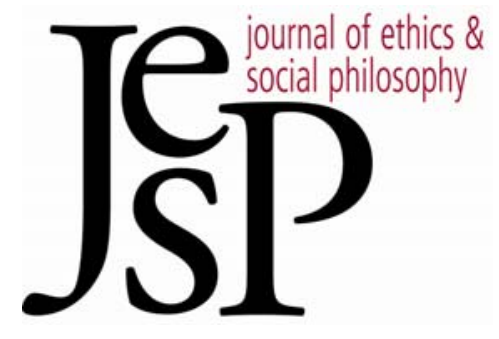

\title{
SAVINg LiVES AND ReSPECTING PERSONS
}

\author{
By GReg Bognar and SAmuel J. Kerstein
}




\section{Saving Lives and Respecting Persons ${ }^{*}$ \\ Greg Bognar and Samuel J. Kerstein}

I

$\mathrm{N}$ THE DISTRIBUTION of resources, persons must be respected, or so many philosophers contend. ${ }^{1}$ Unfortunately, such philosophers often leave it unclear why a certain allocation would respect persons, while another would not. In this paper, we explore what it means to respect persons in resource allocation - specifically in contexts in which scarce, lifesaving resources must be distributed.

As a way of grounding our discussion, we focus on two sorts of cases. We assume in both that our task is to allocate a life-saving resource between different persons. In helping these persons (or a subset of them), we are not discharging a duty of beneficence. Each person needs and wants to get the resource. But since the resource is scarce, we cannot make it available to all. Each person has a claim on the resource in the relatively weak sense that it would be wrong for us to refrain from giving it to her on morally arbitrary grounds (e.g., because we do not like her) or on grounds inappropriate to the context (e.g., because she is not a close friend). Finally, no person in our cases is morally responsible for her need of the resource in any way that would affect her claim on it.

In our first case, we have one indivisible life-saving drug and two patients who are identical in every relevant respect except that one of them is 20 years old and the other one is 70 years old. The patient who does not get the drug will die. If the younger person gets the drug, she will live for many years yet; if the older person gets the drug, she will die of natural causes in a

* For their assistance with this paper we would like to thank Dan W. Brock, Steve Emet, Ryan Fanselow, Aaron Hoitink, Matt King, Matthew Smith, Robert Wachbroit, David Wasserman and our referees, as well as discussants at the University of Maryland's Committee on Politics, Philosophy and Public Policy, the Ethikzentrum Jena, the Rocky Mountain Ethics Conference and the Workshop on Respect for Persons at Emerald Isle, North Carolina.

1 In the context of health care resource allocation, John Harris, for instance, writes that "each person is entitled to be treated with equal concern and respect both in the way health resources are distributed and in the way they are treated generally by health professionals, however much their personal circumstances may differ from that of others." "QALYfying the Value of Life," Journal of Medical Ethics 13 (1987), 117-123, 120. Disability advocates often point out that at least one reason that the institutions and policies that discriminate against people with disabilities are unjust is that they fail to respect these persons. Martha Nussbaum writes, "a satisfactory account of human justice must extend reciprocity and respect to people with impairments, including severe mental impairments." Frontiers of Justice: Disability, Nationality, Species Membership, Cambridge, MA: Harvard University Press, 2006, 92. Finally, on a common interpretation of John Taurek's well-known case for giving equal chances to all who can be saved when not all can be saved, his main argument comes down to an appeal to the idea of equal concern and respect. See Taurek, "Should the Numbers Count?" Philosophy and Public Affairs 6 (1977), 293-316 and Iwao Hirose, Moral Aggregation, manuscript. 
few years. We call this the different-age case.

Most people would agree that the drug should be given to the 20 -yearold patient. One consideration in favor of this choice is that giving the drug to the younger patient does more good: since she will live longer, saving her life creates a larger benefit. Another consideration that many people find relevant is that the older person has had a longer life: she has already had her "fair innings." It would be unfair to the younger person to deny her the chance of a full human life, given that the older person has already had such a life. ${ }^{2}$

It is not immediately clear, however, that giving priority to the younger person is compatible with the idea of respect for persons - at least in the sense of treating the two patients with the equal concern and respect that is morally owed to them. Assuming that both patients want to be saved and they both have a claim on the drug, it seems that we show less concern for the older person and we respect her wish to go on living less than the wish of the younger person. Giving priority to the 20-year-old seems to involve not treating both patients with equal concern and respect, although it seems to be the recommended course of action on both benefit-maximizing and fairness grounds.

In our second case, we have to decide whether we save one person or five persons from certain death. Perhaps there were two traffic accidents, and one person was injured in the first and five persons were injured in the second. All the accident victims have immediately life-threatening injuries, and they are alike in all relevant respects. We can, however, reach only one of the accident scenes. If we save the one person, the five persons in the other accident will die; if we save the five, the one person will die. We call this the different-number case.

On benefit-maximizing grounds, we should save the five. But some philosophers argue that it would be unfair to give no chance to the one person at all: if we did that, we would fail to show proper respect for her - perhaps because her claim is not taken into consideration at all. On this view, benefit-maximizing and fairness considerations point in different directions. Others argue that it is possible to save the five persons while giving no chance to the one person without failing to show proper respect for herperhaps because her claim is taken into consideration just as much as those of the others, but it is outweighed by them in one way or another. In this example, both sides appeal to the idea of respect for persons.

In what follows, we examine three accounts of respect for persons. We use these examples as test cases against which their implications can be as-

2 For the fair innings argument, see John Harris, The Value of Life: An Introduction to Medical Ethics, London: Routledge \& Kegan Paul, 1985; for a recent discussion, see Greg Bognar, “Age-Weighting," Economics and Philosophy 24 (2008), 167-189. 
sessed. ${ }^{3}$ The first two accounts have been discussed extensively in the literature. However, their implications in examples such as ours have not been adequately explored. After briefly characterizing the accounts, we argue that they have implications in our examples which many would find implausible. We then outline an alternative account - one that has not received the attention it deserves. We argue that it accords with the considered judgments of many people at least as well as its rivals. But we also indicate some of its implications that might be unattractive, and suggest some ways of developing it further.

Before turning to the accounts, let us make two caveats. First, respecting persons is often interpreted as calling for treating persons with equal concern and respect. But concern and respect are different attitudes and they are likely to involve different moral requirements. As a parent, you are required to treat all your children with equal concern, but you are not required to have the same concern toward other people's children. You might, however, be required to treat all children with the same respect. In this paper, we set aside the problems that concern raises.

Second, treating persons with the respect that is morally owed to them is sometimes understood simply as acting toward them in ways that can be justified. If it is justified to give the life-saving drug to the younger person, then this course of action involves treating both the young and the old persons with proper respect. On this view, respect for persons is ultimately not a separate principle, but just a shorthand way of saying that some action or policy is right, permissible or just. Those who take this view will find little of interest in this paper, since we consider respect for persons an independent principle with its own moral weight. This seems to us the correct view. It makes sense to say that an action, policy or institution is wrong or unjust because it fails to properly respect persons.

\section{The Equal Worth Account}

One familiar account, suggested, for example, by Jeff McMahan, connects the notion of respect for persons to the idea of the worth of a person. ${ }^{4}$ On this view, persons have a special value, or worth, in virtue of having certain psychological capacities: the capacity to perceive and understand the world, to form desires and life plans, to reflect and deliberate on these desires and life plans, and so on. Chief among these capacities is the person's autonomy or "the capacity to direct one's life in accordance with values that one reflect-

\footnotetext{
3 Although our test cases are stylized, they are not without practical relevance. Choices about life-saving must be made in the allocation of organs for transplants, vaccination in pandemic flu and beds in intensive care units. In resource-poor countries, disease control priority-setting (e.g., for antiretroviral therapy for HIV infection) is a common problem.

${ }^{4}$ Jeff McMahan, The Ethics of Killing: Problems at the Margins of Life, New York: Oxford University Press, 2002, 256, 261, 478.
} 
ively endorses." ${ }_{5}$ We shall call this view the equal worth account.

A person's worth is a threshold concept: each person who has autonomy (as well as the other necessary psychological capacities) has worth equal to that of every other person, no matter how well- or ill-developed her autonomy (or those other capacities) may be. Those whose autonomy or other cognitive capacities fall below the threshold do not count as persons in the full moral sense, and hence have lower or no moral worth. What is morally owed to such beings is a difficult problem that we set aside.

The worth of a person is entirely independent of how well her life goes. Thus, this sort of value does not vary according to the level of a person's well-being. Moreover, a person's worth is neither a function of her instrumental value to others nor of her impersonal value - that is, of her value from the "point of view" of the universe (if this notion is coherent). Finally, the worth of persons is not a value to be maximized, for instance, by creating as many persons as possible. It is, rather, a value that attaches to extant persons in virtue of which those persons are to be respected.

On this account, respecting a person involves respecting her as a being who has worth as just described. But how do we do that? McMahan suggests that we respect a person if and only if we show proper respect for both the person's good and her autonomous will concerning how her own life should go. ${ }^{6}$ Even though a person's worth does not vary according to her level of well-being, showing proper respect for the person can involve taking her well-being into account. A terminally ill person who is suffering greatly does not thereby have any less worth than anyone else, but showing proper respect for her might involve taking her suffering into account by helping her to end her existence, as long as she has autonomously willed that we do so. Thus, on this account, an action can manifest respect for a person's worth even if it contributes to destroying the capacities that constitute the basis of this worth. 7

What are the implications of the equal worth account for our two test cases? Consider the different-age case first. We have one indivisible life-saving drug that can extend the life of a 20 -year-old for many years or the life of a 70-year-old for a few. The good for each person is to survive, and, by assumption, each has autonomously chosen to try to do so. Therefore what would be respectful toward each of them is to give each an equal chance of getting the drug. In doing that we would be giving equal weight to each person's worth, regardless of the greater benefits that might be realized by allotting it straightaway to the younger person, and regardless of the fact that the older person has already had a full human life while the younger person has not.

${ }^{5}$ McMahan, 256.

${ }^{6}$ McMahan, 482.

7 See McMahan, 482-483 and 478. 
One might object that we should rely on a randomizing procedure which, instead of giving both an equal chance of getting the drug, gives the 20 -year-old a greater chance. For, as a younger person, does she not stand to benefit a lot more from the drug than the older person? But this objection is misguided. According to the equal worth account, respecting a person involves both respecting her autonomous will and promoting her good (given that this is what she autonomously wants). But the requirement of promoting the person's good does not vary with the amount of the good: we have this requirement regardless of how extensive that good may be. So the fact that the younger person stands to benefit more from the drug than the older person provides no grounds for giving her a greater chance to get it. It would be not be respectful to give the two persons different chances.

In our second example, we have to decide whether we save one person or five persons. We called this the different-number case. By assumption, all persons autonomously want to be saved, and, since they all have equal worth, we might rely on a randomizing procedure that gives equal chances to all for instance, by tossing a fair coin to decide whether we save the one or the five. Hence all persons have a 50 percent chance of being saved. On this solution, we respect each person: through giving each an equal chance for survival, we give equal weight to each person's worth. If we instead straightaway saved the five, one might argue, we would not show proper respect to the one not saved: for we would ignore what she autonomously wants and what is good for her by not giving her a chance to realize this good even though it was in our power to do so.

The equal chances solution implies that respect for persons would require everyone to have a 50 percent chance of being saved even if we have only one person in one of the groups and a million in the other. Many people find this implication counterintuitive. Of course, proponents of the equal worth account might argue that in this case the greater benefit of saving a million people would justify not showing proper respect to the one person. But this reply is not entirely satisfying. It accepts that which many find implausible in benefit-maximizing views - that saving the greater number is justified even though it is unfair to the person whom we let die. Perhaps an alternative solution that implies that at least in some cases we can give higher chances to the greater number without disrespecting those who are not saved would accord better with our intuitions.

Thus, it might be suggested that the equal worth account is compatible with giving proportional chances through, for example, a weighted lottery. On this procedure, both groups of persons might be assigned chances which are proportional to the number of members they have. The group consisting of five persons would have a five-in-six chance to be selected; the single person would have a one-in-six chance. The way we might think about this procedure is that each person has an equal (one-in-six) chance to be selected, but 
the chances of the five persons in the larger group are pooled. ${ }^{8}$

This procedure also seems compatible with the equal worth account. If we give an equal one-in-six chance to each person, we show proper respect for her equal worth by giving equal consideration to her autonomous pursuit of her good. Moreover, by allowing the chances of the members of different groups to be pooled, we also show proper respect for their autonomous will - since, by assumption, they would want their chances of survival to be as great as possible.

Furthermore, one could perhaps even argue that a policy of saving the greater number without any randomizing procedure is also compatible with the equal worth account. Here is one suggestion how. You consider the autonomous will and good of the single person on one side and the autonomous will and good of a person on the other side. The claims which are based on their worth are equally pressing and they are equally balanced. That leaves the claims of the remaining four. Since these claims remain, they determine that we should save the greater number - in our example, the group of five. If the additional claims of these four people could not tip the balance, they would be ignored, and we would fail to respect these persons. ${ }^{9}$

Once again, it seems to us that this procedure is compatible with the equal worth account. The single person who is not saved cannot complain that her autonomous will and good are considered less than those of others: her worth is taken into account just as much as anybody else's, even though it is neutralized by its being balanced against that of another. ${ }^{10}$

Consequently, it seems that the equal worth account is compatible with at least three conflicting procedures for determining whom to save. Of course, we could look at this conclusion two ways: if respect for persons is compatible with all these different solutions, we can choose between them on the basis of further moral argument. The glass is half full. On the other hand, the conclusion makes appeals to respect for persons in different-num-

8 See Frances M. Kamm, Morality, Mortality, Volume 1: Death and Whom to Save from It, New York: Oxford University Press, 1993, 130-131.

9 Frances Kamm calls this the Balancing Argument. See Kamm, Morality, Mortality, 116-121; see also T. M. Scanlon, What We Owe to Each Other, Cambridge, MA: Harvard University Press, 1998, 232-233.

${ }^{10}$ Some might nevertheless object that neither of the latter two procedures gives proper respect to the single person who has a smaller (or no) chance of being saved. Given that each person autonomously wills her chances of survival to be as great as possible, how is she shown proper respect when her chances fall short of this? Perhaps she is not. But if we accept this, then we must also accept that the single person is not shown proper respect if we give equal chances to her and to the group of five. For a 50 percent chance of survival is not a maximal chance. But then respect for persons seems to require that everybody's autonomous wants are satisfied completely, which is impossible in the kind of cases we are considering. On this interpretation, the equal worth account leaves us with either a moral dilemma or a moral gap. In other words, it entails that either we act wrongly no matter what we do, or it gives no guidance, leaving us helpless in these cases. And we could not escape the moral dilemma by not saving anyone: saving no one is surely incompatible with respect for persons. 
ber cases quite unhelpful: proponents of different solutions do not advance the debate by defending their view in terms of respect for persons. The glass is half empty. But since the equal worth account definitely has counterintuitive implications in different-age cases, we are inclined to think that the glass has very little in it at all.

\section{A Kantian Account}

The idea of respect for persons goes back, of course, at least to Kant. We now consider an account that is based on his Formula of Humanity (FH): "So act that you use bumanity, whether in your own person or in the person of any other, always at the same time as an end, never merely as a means." ${ }_{11}$ Our discussion centers on (what we call) the respect expression approach to FH. This interpretation is highly influential and relevant to the sorts of problems that our cases raise.12

According to the respect expression approach, FH amounts to the following (RFH): Act always in a way that expresses respect for the worth of bumanity, in one's own person as well as that of another. Of course, RFH is to be understood as a categorical imperative: a principle that all of us have an overriding obligation to conform to. But we need to keep in mind from the outset that a type of action might express respect for the worth of humanity simply by virtue of expressing no disrespect for it. RFH does not entail that every morally permissible type of action involves some positive affirmation of the value of humanity.

We should also note that Kant uses "humanity" interchangeably with "rational nature." 13 In doing so, he suggests that having humanity involves having certain rational capacities. Among these are the capacities to set and pursue ends and to conform to self-given moral imperatives purely out of respect for these imperatives. ${ }^{14}$ In what follows, we use the terms "humanity," "rational nature" and "capacity of rational choice" interchangeably. Furthermore, it is important to remember that rational nature is a threshold concept. If one has the set of capacities that are constitutive of it, one has it, no matter how well- or ill-developed those capacities may be.

$\mathrm{RFH}$ commands that we act always in a way that expresses respect for

11 Immanuel Kant, Groundwork of the Metaphysics of Morals, in Immanuel Kant: Practical Philosophy, Mary Gregor (trans.), Cambridge: Cambridge University Press, 1996, 429. (We refer to Preussische Akademie (vol. IV) pagination, which is included in the margins of the Gregor translation. We cite the Groundwork as GMS.)

12 Our discussion follows the interpretation of Allen Wood, Kant's Ethical Thought, New York: Cambridge University Press, 1999, 111-155. There are, of course, other textually plausible interpretations of FH. See, for example, Oliver Sensen, "Dignity and the Formula of Humanity (ad IV 429, IV 435)," in Jens Timmermann (ed.), Kant's "Groundwork of the Metaphysics of Morals": A Critical Guide, Cambridge: Cambridge University Press, 2010, 102-118.

13 See, for example, GMS 439.

14 See Thomas E. Hill Jr., Dignity and Practical Reason in Kant's Moral Theory, Ithaca, NY: Cornell University Press, 1992, 38-41. 
the worth or, equivalently, the value of humanity. But what is that value? First of all, it is a value that attaches to something already extant - an independently existing end - rather than to something that needs to be brought into existence. An appropriate reaction to the value of the sort that humanity has is to honor, cherish or protect it, rather than to bring more of it about. Second, humanity has absolute or unconditional worth. ${ }^{15}$ That means it is good under every possible condition - that is, in every possible context, in which it exists. It is good no matter how it came to exist or what the effects of its existence may be. Moreover, if something is unconditionally good, then neither what it affects nor what happens to it has any bearing on the degree of its goodness. ${ }^{16}$

Third, humanity has incomparable worth. That is, it has no equivalent for which it can be legitimately exchanged. ${ }^{17}$ Humanity can never be legitimately sacrificed for or replaced by something with mere price. Not even all the gold in Fort Knox would truly compensate for the killing of one rational agent. ${ }^{18}$ Moreover, since humanity possesses incomparable worth, it cannot even be legitimately sacrificed for or replaced by something else with such worth. It makes no sense to say that in some context one or more instances of humanity have more or less value than one or more other instances of humanity. In Kant's view, everything that lacks incomparable worth has mere price, including human happiness and well-being. In Kant's terms, to say that humanity is unconditionally and incomparably valuable is to say that it has "dignity." In his view, humanity and humanity alone has dignity.

In order to derive duties from RFH to act (or refrain from acting) in some way, we must rely on intermediate premises: premises that specify whether some sort of conduct expresses respect for the worth of humanity. The following is an example of an intermediate premise: committing suicide to avoid suffering expresses disrespect for the value of humanity. Assuming that this premise is true, it follows that we have a duty not to commit suicide to avoid suffering.

According to the respect expression interpretation of $\mathrm{FH}$, an action is

15 GMS 428.

${ }^{16}$ Kant says that a good will is good without qualification (GMS 393), which we take to be equivalent to saying that it is unconditionally good. And it is clear that a good will is not only good in all possible circumstances in which it appears, but that its level of goodness does not vary according to its effects. Even if a good will "were completely powerless to carry out its aims; if with even its utmost effort it still accomplished nothing, so that only good will itself remained ... even then it would still, like a jewel, glisten in its own right, as something that had its full worth in itself' (GMS 394).

17 GMS 434-436 and Immanuel Kant, The Metaphysics of Morals, in Immanuel Kant: Practical Philosophy, Mary Gregor (trans.), Cambridge: Cambridge University Press, 1996, 434-435, 462. (We are referring to Preussische Akademie (vol. VI) pagination, which is included in the margins of the Gregor translation.) See also Hill, Dignity and Practical Reason, 47-49.

18 We are assuming here and assume throughout that a human being's rational nature is extinguished if she dies; it does not endure in an afterlife. 
wrong just in case it fails to express respect for the value of humanity. But any action that fails to express respect for this value does so at least in part by suggesting an inaccurate message regarding what the value is. An explanation of what makes the suicide discussed above wrong would necessarily have to make the point that it expresses a false message: the message that some person (that is, the one about to kill herself) does not have dignity. If an action expresses such a message, then it fails to express respect for the value of humanity, and it is morally impermissible.

It is not always easy to discern whether an action expresses respect for the value of humanity. In particular, it can be difficult to determine whether it sends a message that is compatible with the view that humanity has dignity - not necessarily because the Kantian notion of dignity is vague, but rather because what an action "means" is subject to interpretation. So it is possible that our interpretations of various actions below are in error. But if they are, then those who reject them must be able to say why. If no rational argument concerning the meaning of actions is possible, then the respect expression approach renders $\mathrm{FH}$ too indeterminate to be usable.

With this caveat, let us return to our examples. Suppose we give the lifesaving drug to the younger patient in the different-age case on the grounds that, since she will live longer, we thereby bring about more well-being. If we do this, we express disrespect for the value of the older patient's rational nature. (This is an intermediate premise.) Let us explain.

An action might express respect for the value of a person's rational nature (or capacity of rational choice) through expressing respect for her $e x$ ercise of this capacity. Suppose, for example, that a colleague has lent you money, but, as she informed you, needs the loan repaid by a certain date so she can make a down payment on a house. If you repay the loan on time, then your action expresses respect for the value of her capacity of rational choice through expressing respect for her exercise of this capacity - that is, through expressing respect for her pursuit of the end of buying a house.

But saving the younger patient would obviously not express respect for the older patient's rational nature through expressing respect for her exercise of it. For the older patient is not ready to step aside; by assumption, she is striving to survive. We do not, of course, respect this exercise of her capacity of rational choice by making a decision that in effect makes it impossible for her to attain her end.

An action might express respect for the value of a person's capacity of rational choice not by expressing respect for a particular instance of her exercising this capacity, but by expressing respect for the value of the capacity itself. Consider again the action of preventing a person from committing suicide: by preserving this person's capacity of rational choice, this action would presumably express respect for it. But it would not honor her exercise of that capacity.

In order for our action to express respect for the value of humanity, it 
must not suggest an inaccurate message regarding that value. Giving the drug to the younger patient on the grounds that doing so yields more well-being, however, would send a message that is incompatible with idea that the older patient's rational nature has dignity. Just like the younger patient, the older patient has a claim to treatment. Whether or not we give it to her is not just a matter of whom we choose as an object of our beneficence. Our action would suggest that something of mere price, namely well-being, tips the scales in favor of saving one person, the younger, rather than saving another, the older. But that message obviously conflicts with the notion that the value of humanity is incomparable.

One might suggest that we give the drug to the younger patient not on the grounds that we thereby maximize well-being, but on the grounds that the older patient has already had a full human life - that is, her "fair innings." But this action would also send a message contrary to the notion that humanity has dignity. For it would suggest that an instance of rational nature that has endured sufficiently long (making for a full human existence) has less value than an instance that has been around for a shorter time. But this contradicts the notion that the value of humanity is unconditional: whether a life has been long enough to constitute a full human life does not affect this value. And, again, the value of rational nature is incomparable: the value of a full rational existence cannot be weighed against the value of an incomplete one. So we cannot conclude that the value of the one is less than that of the other.

We have argued that if we give the drug to the younger patient on either of these grounds, then we express disrespect for the value of the older patient's rational nature. But what resource-distributing action in this difficult scenario would express proper respect for the value of each patient? It seems that flipping a fair coin to decide to whom to give the life-saving drug would do so. For this action would send the message that each patient is valuable; each is worthy of having an equal chance to be saved. And this action would also suggest that the longer existence or the greater quantity of well-being to be had by the younger patient fails to make her more valuable than the older one. The action does not seem to run afoul of the notion that persons have incomparable and unconditional value - that is, dignity.

Let us now turn to the different-number case. Which action, if any, would express respect for the dignity of each person's capacity of rational choice? As we have seen, an action might express respect for the value of this capacity through expressing respect for one's exercise of it or through expressing respect for the capacity itself. But, just as in the different-age case, it is difficult to see how we could respect the exercise of the capacity of rational choice of all of the persons involved, given that by our assumption they are all striving to survive. Hence we will focus here on the latter mode of expressing respect.

Saving the five simply on the grounds that we thereby preserve more 
value would obviously send a message that clashes with the notion that humanity has dignity. For it would imply that five persons have greater value than one.

We might, of course, give each set of persons chances proportional to their number - that is, a five-in-six chance for the group of five and a one-insix chance for the single person. One basis for doing so would be the idea that the value of each person initially entitles her to an equal chance of being saved (one-in-six), but that chance gets pooled with those of others in her group, if there are any. But adopting this procedure would likely send the message that the value of humanity is comparable. In particular, it would encourage the notion that five persons have greater value than one person. For if the basis for initially giving each person an equal chance is the value of her humanity, it is natural to think that the basis for allowing the pooling of chances among several people is the notion that several instances of humanity have more value than a single instance. ${ }^{19}$

The Kantian account also seems to rule out saving the greater number through "balancing" claims - at least if the basis for balancing them is the value of the persons who have those claims. Suppose we balance the claim of one member of the group of five against the claim of the single person. Since there remain four persons in the group of five whose claims have not been balanced by the claims of anyone, we save all the members in this group. In short, the claims of the five outweigh the claim of the one. But why?20 One very natural response is to say that the five persons who are making the claims together have a value that is greater than that of the one. But if this is our reason, then by saving the five we express the idea that the value of persons is comparable.

Of course, someone might refuse to choose between saving the one or the five on the grounds that there is no way to make the choice that would avoid sending the message that persons fail to have incomparable value. She might think that adopting any procedure to determine which set of persons to select would suggest that some person (or group of persons) has greater or lesser value than another. But would not walking away also suggest a message inconsistent with the idea that persons have dignity? Would it not imply that no one was worth saving?

If one tries in the different-number case to proceed on the basis of the

19 Jens Timmermann's “individualist lottery," which he claims is based on a "broadly Kantian ethical theory," also gives proportional chances to each person, but the basis for doing so is different. We cannot discuss his proposal here. See Timmerman, "The Individualist Lottery: How People Count, But Not their Numbers,” Analysis 64 (2004), 106-112.

${ }^{20}$ David Wasserman and Alan Strudler have pressed this sort of question in "Can a Nonconsequentialist Count Lives?" Philosophy and Public Affairs 31 (2003), 71-94, especially 89-93. Like Wasserman and Strudler, we fail to find self-evident the assertion that the claim of the one person can "balance" only the claim of one among the five. Some defense of this assertion is needed. And to our knowledge no defense which is both plausible and avoids sending the message that the value of persons is comparable has been offered. 
conviction that humanity has dignity, it seems that one would give each set of persons, the one and the five, an equal chance of being saved. Unlike the proportional chances and balancing procedures as we described them, doing this would not leave the impression that five persons together have a greater value than one. And, unlike refusing to save anyone, it would not suggest that no one was worth saving.

In sum, the Kantian account is challenging to apply to our cases. It is not easy to determine what message a particular allocation procedure conveys. But in the different-age case the account has implications that clash with common considered moral judgments. For many of us believe that we ought to save the younger person, rather than to give equal chances to both. And we just do not see how saving the younger person could express respect for the dignity of both. In the different-number case, we have not here eliminated the possibility that doing something other than giving equal chances of being saved to the five and to the one would express respect for the dignity of everyone concerned. However, this procedure strikes us as the candidate most likely to do so. And, while this solution may seem unobjectionable to some, others may find it unattractive - especially given that, by the same rationale, if the set of persons we could save on one side were much larger (say, one million), then we would still have to flip a coin.

\section{A Three-Tiered Account}

We now present an alternative account of respect for persons. This account has several components in common with the equal worth and the Kantian accounts discussed above. Just like the equal worth account, it holds that people have worth in virtue of being persons and that the basis of their worth is the presence of certain psychological capacities, including autonomy, that constitute personhood. Here we leave open the question of precisely which capacities these are. We also hold that each person who has these capacities has worth that is equal to the worth of other persons and that the worth of persons is independent of their well-being. Like both of the other accounts, ours maintains that respecting the worth of persons does not involve bringing as many persons as possible into existence. Finally, our account agrees with the Kantian account that the worth of persons is unconditional: a person has worth in every context and this worth is independent of the history and consequences of the person's existence.

However, our account differs from the Kantian account in two important respects. We do not hold that the worth of persons is incomparable. On the Kantian view, humanity, in virtue of which a person has worth, cannot be legitimately exchanged for something that has "mere price" - that is, anything that has a different sort of value, like the happiness of other people. Neither can it be legitimately exchanged for anything that has the same sort of value - that is, with other instances of humanity. In our view, the worth 
of persons is only one of many competing values - albeit a central and fundamentally important one. In particular, we do not assume that the worth of a person is the sort of value that can never be legitimately exchanged for something else that has the same sort of value. Second, the Kantian account holds that if an action fails to respect persons, then we ought not to perform it, all things considered. For on this account respect for persons is commanded categorically by the supreme principle of morality. Our account, by contrast, aims to serve as a basis for determining what respect for persons demands. (Here, of course, we focus only on what it demands in the allocation of scarce, life-saving resources.) But we do not claim that one never ought, all things considered, to act contrary to what respect for persons demands. Below we discuss cases in which considerations of distributive justice might override those of respect for persons.

Our account holds that in virtue of possessing certain capacities, including autonomy, some beings have a special, unconditional value or worth. ${ }^{21}$ To respect persons is to respect the value of these capacities. How do we do that? We do not here try to answer this question for every context. But it will help us arrive at an answer adequate for the context we describe to think about actions that respect things other than persons.

Suppose, for example, that we hold a certain painting to have exceptional aesthetic value. One way of respecting this value is to do our best to maintain the painting in existence by, say, protecting it against destruction from insects, excessive heat and so forth. Or suppose that we hold a stand of thousand-year-old Sequoia trees to be of special worth. One way of respecting this worth would be to do what is in our power to prevent the forest from being destroyed to make way for a mall. Acting with respect for the special value of a thing can and often does involve trying to preserve that thing.

Now consider the context of the different-age and different-number cases. It is our job to allocate scarce, life-saving resources among persons who, we hold, have a special, unconditional value by virtue of having a set of capacities, including autonomy. Each of these persons has, we assume, re-

${ }^{21}$ In this paper, we take only initial steps toward a defense of the account that the worth of persons, as we characterize it, lies in their possessing certain psychological capacities. In our view, a defense of the account would, among other things, require demonstrating that the view's implications in a wide range of contexts are more plausible than those of its rivals, as well as showing that it harmonizes at least as well as its rivals with our best metaethical and psychological theories. Contemporary Kantians have developed sophisticated a priori arguments with which they claim to show that, given some plausible assumptions about our rational agency (e.g., that we have reasons for acting), we are rationally compelled to hold persons to have a special worth. (See, for example, Christine Korsgaard, The Sources of Normativity, Cambridge: Cambridge University Press, 1996, and Allen Wood, Kant's Ethical Thought.) One of us has elsewhere tried to point out serious flaws in these arguments (Samuel J. Kerstein, Kant's Search for the Supreme Principle of Morality, Cambridge: Cambridge University Press, 2002). We are skeptical as to whether they or ones like them hold much hope of adequately grounding any particular view of the worth of persons. 
flectively endorsed the aim of preserving her own life. Our account holds that acting with respect for the worth of these persons requires maximally preserving them, subject to the constraint, to be explained below, that in doing so we not treat anyone merely as a means. Respect for persons thus here involves preserving, in certain permissible ways and as best as we can, those persons.

Someone might grant that acting with respect for something that has a special value often involves trying to preserve it. But he might point out that this is not always so. For example, some hold the United States flag to have a special value. They believe that acting with respect for the value of a particular flag can require destroying it - namely when it has become so faded and worn as no longer to be a fitting emblem for the nation. ${ }^{22}$ So it seems that we have reason to doubt whether acting with respect for the worth of persons typically involves trying to preserve them.

In reply, there seems to be an important difference between the value being attributed to flags and to persons. Our account holds that, as long as a person has the capacities that constitute personhood, she has a special value - one that does not diminish no matter what happens to her. But those who hold that a United States flag has a special value seem to hold its value to be conditional - that is, such that it diminishes if the flag becomes faded and worn. Indeed, it seems that, in their view, it is because a faded and worn flag has lost some of its value to serve as a fitting emblem for the nation that it is appropriate to destroy it. So the appeal to things with special value like flags seems not really to threaten the notion that in the cases we describe, respecting the value of persons involves maximally preserving them.

Moreover, our account does not commit us to the view that respect for the value of a person always requires preserving her for as long as we can. As we explain below, an attempt to preserve a person might involve violating the constraint against treating people merely as means. Besides, we do not wish to rule out the possibility that failing to preserve a person might be respectful of her special value. We can, for example, imagine a situation in which a terminally ill person autonomously wills to end her life and is so bent on doing so that her rational agency is, as it were, permanently exhausted by this pursuit. Practically speaking, she can pursue no other ends. The action most respectful of the special value possessed by this person might be that of supporting her in her effort to die. For in this case respecting the value of her $c a$ pacity of rational choice might amount to respecting her one mode of exercising this capacity.

In the different-age and different-number cases, we believe that respect for the special value of persons requires maximally preserving them, subject

${ }^{22}$ See U.S. Code Title 4, Chapter 1, $\sqrt{8}$. Respect for flag and John Luckey "Flag Protection: A Brief History and Summary of Recent Supreme Court Decisions and Proposed Constitutional Amendment," Congressional Research Service Report for Congress, 19 May 2005. 
to the constraint that we not treat anyone merely as a means. Let us now explain in greater detail what we mean, first, by maximally preserving persons and, second, by the mere-means constraint.

Persons can be preserved along two dimensions. First, we can preserve a person by extending the period of time in which she possesses the capacities constitutive of personhood. For the sake of simplicity, we say that preserving persons along this dimension involves preserving "person years." 23 Second, we can preserve persons by keeping them in existence. Again for the sake of simplicity, we say that this involves preservation along the "person numbers" dimension. To illustrate: if we save five people for two years, then on the person-years dimension we preserve 10 years, while on the person-numbers dimension we preserve five people. We believe that reflective common sense values the preservation of persons along these two dimensions. In the resource allocation situations we are concerned with, respect for persons demands that we maximally preserve them along both, subject to an important constraint that we are about to explain. Of course, there can be situations in which maximizing preservation along one dimension does not maximize it on the other. We discuss these cases below.

Preserving persons along these dimensions is subject to the constraint that doing so not involve treating any persons merely as means. We offer no $a$ priori justification of this constraint. But we contend that it, or something very much like it, seems to be endorsed by our considered judgments regarding what respecting persons amounts to. Giving a full account of treating another merely as a means is beyond the scope of this paper, but the following, somewhat oversimplified, account should suffice for our purposes. A person treats another person as a means - or, in our view equivalently, uses another person as a means - if she intentionally does something to the other's body or mind in order to realize one of her ends and she intends the other's body or mind to contribute to her end's realization. In our view, a person does not treat another as a means unless she intends the other's presence or participation to contribute to the end's realization. ${ }^{24}$ A person treats another person merely as a means - or, which we once again take to be equivalent, uses the other merely as a means - if it is reasonable for her to believe that something she has done or is doing to the other person renders that person unable to consent to her treating him as a means to her aim. A person is unable to consent to another person's treating him as a means if he has no opportunity to forestall the action by withholding his agreement to it. ${ }^{25}$

${ }^{23}$ Using years as a unit is evidently arbitrary, and we do so only for their convenience in the discussion of examples. Also, extending life does not necessarily amount to preserving a person, or extending person years. An individual can be rescued from death, for example, only to live in a persistent vegetative state.

${ }^{24}$ See Thomas Scanlon, Moral Dimensions: Permissibility, Meaning, Blame, Cambridge, MA: Harvard University Press, 2008, 106-107.

25 See Onora O’Neill, "Between Consenting Adults," in Constructions of Reason, Cambridge: 
For example, suppose several patients in a hospital are in immediate need of different organs. One needs a kidney, another needs a heart, a third needs a liver and so forth. If we killed a healthy patient who is there for a regular check-up and divided her organs among the other patients, they all would be saved. Suppose that in order to save the other patients, we go ahead and do so, without giving the healthy patient any opportunity to prevent our action. We therefore treat her merely as a means and violate this constraint.

For another illustration of the mere-means constraint, consider a terminally ill patient whose remaining life would be filled with great suffering. As long as this person has the necessary capacities, she has worth that is equal to that which any other person has by virtue of possessing those capacities. We might believe that respecting this person's worth would involve attempting to prolong her existence as a person. For we can imagine that, unlike the person described above, this person's rational agency is not exhausted by her will to end her life: she can and does pursue other projects. Even so we could legitimately make an attempt to prolong her life only if we reasonably believed that our treatment of her did not render her unable to prevent our efforts by withholding her consent to them. Preserving the patient's personhood by deceiving or coercing her would violate the meremeans constraint.

It is worth noting some of the ways in which our discussion of the mere-means constraint is oversimplified. An obvious question is whether the constraint should be regarded as absolute. If, as we believe, it should not be so regarded, what should the threshold for overriding it be? We here leave aside this difficult issue. Moreover, in some cases a person is justified in coercing, forcefully defending herself against or deceiving another person, or so many of us believe. But our discussion implies that in some of these cases the person treats the other merely as a means and thus, presumably, acts wrongly. To use an example of (what many of us take to be) justified deception: suppose that in order to make your spouse's birthday party a surprise for her, you need to lie to her about your whereabouts on a certain day. According to our simplified account, if you go ahead and lie to her for this purpose, you treat her merely as a means. For your deception makes her unable to avert, by withholding her consent, your using her for your purpose. A more complex account of treating others merely as means would enable us to avoid this implication as well as those that might arise in cases of justifiable coercion and self-defense. ${ }^{26}$

In any case, the three tiers of our account of what respect for persons requires in contexts of the allocation of scarce, life-saving resources should now be in focus. Of course, at the base of the account is the view that persons have worth as we describe it. One of the account's tiers consists in the

Cambridge University Press, 1989, 105-125.

26 See Samuel J. Kerstein, “Treating Others Merely as Means,” Utilitas 21 (2009), 163-180. 
mere-means constraint, while the other two are imperatives to maximize person preservation along the person-years and person-numbers dimensions.

The implications of this account for our two test cases are relatively straightforward. Respect for persons requires the preservation of personhood along the person-years and the person-numbers dimensions. For the moment, suppose that our action does not involve treating anyone merely as a means. Consider then the different-age case. Since in this choice there is no conflict with respect to the number of persons, only the person-years dimension is relevant; thus, we should give the drug to the 20 -year-old, for we thereby preserve personhood for a longer period.

Consider the different-number case now. We assumed that all the persons involved are alike in all relevant respects, including their expectation of life should they be saved. The account at hand would recommend saving the five both because we thereby best preserve personhood along the personnumbers dimension, and because by saving the five we best preserve personhood along the person-years dimension. Of course, we might be faced with a different case in which the expectation of life of the five adds up to equal the expectation of life of the one person; in that case, there would be no difference along the person-years dimension. Other things being equal, we should still save the five because it best preserves personhood along the person-numbers dimension.

According to the three-tiered account, it is permissible to save the greater number without giving equal chances for the one person and the group of five, or even without giving them proportional chances. However, the explanation for the permissibility of this action does not appeal to the idea of balancing claims; rather, it appeals to the idea of preserving personhood the best we can.

One might object that in our analysis we end up treating the person not saved merely as means in both sorts of cases, and hence that we are not permitted to give priority to the greater number or to the person whose expectation of life is greater. But this objection misunderstands the mere-means constraint. For in neither case do we use at all, let alone use merely as a means, the person whom we do not save. That is, in neither case do we intend the presence or participation of this person to contribute to the realization of our end, which is, of course, to preserve personhood the best we can, both along the person-numbers and person-years dimensions. We do not depend in any way on the presence or participation of the single person in order to save the five others, or on the presence or participation of the older person in order to save the younger.

A further protest one might lodge is the following. Respect demands that the older patient and the single person be given at least some chance of being preserved. But if we conform to the three-tiered account, they receive no chance. Therefore, we fail to respect them.

But consider this. There is a moral constraint that governs our treatment 
of these persons: if treating them merely as means were the only way to save others, we would be forbidden by this constraint to use them in this way. It just so happens that, in the cases we are concerned with, we are not tempted to treat those we do not save merely as means; for using them at all would in no way serve our life-saving purposes. Moreover, we respect those who in the end perish by giving their preservation every bit as much weight as anyone else's preservation in the process of determining how to proceed. For example, a person year of an individual we do not end up saving counts just as much in our calculations as a person year of someone we do end up saving. Hence we actually respect in two ways the ones whom we do not save in the different-age and different-number cases.

Two further objections might be more serious. Suppose you can save a person for a year, and another person for 51 weeks. Is it compatible with respecting persons to choose the first person on the grounds that we thereby best preserve personhood, as the three-tiered account seems to suggest? F. M. Kamm argues that there are "irrelevant utilities," or benefits and harms that are not sufficient to justify a choice between life and death, since the difference between them is too small. ${ }^{27}$ If she is correct about this, then perhaps the person-years dimension should be invoked as a basis for choosing whom to save only if the difference between the time that can be preserved by saving one rather than another passes a certain threshold. But it is not obvious how to define that threshold.

One might also object that the three-tiered account is too vague. In particular, as presented thus far, it fails to answer the question of how two of its components - namely, preservation along the person-years and the personnumbers dimensions - should be weighted relative to one another in cases in which preserving one set of persons would yield a higher value on one dimension and preserving another set would yield a higher value on the other. For instance, suppose we can save one person for 11 years or five persons for two years each. Choosing to save the one person would best preserve personhood along the person-years dimension; choosing to save the five people would best preserve personhood along the person-numbers dimension. How should we proceed?

Any proposal is likely to become complicated and controversial as we consider various combinations of different-number and different-age cases where one set of persons has a higher value on one dimension while the other set has a higher value on the other. But here is a suggestion we believe to be well worth pursuing. We begin by determining the proportion between the values possessed by the two sets of persons on each dimension. The set that contributes the higher value to the proportion on a given dimension is "favored" on that dimension. We then determine which proportion along the person-years and person-numbers dimensions is greater. We preserve the set

27 See Kamm, Morality, Mortality, 101-102. 
of persons that is favored in the proportion that yields that higher number.

Returning to the example above illustrates this "comparative proportion procedure." ${ }_{28}$ We have to choose between saving one person for 11 years or five persons for two years each. The one person has a higher value on the person-years dimension, but the group of five has a higher value on the person-numbers dimension. On the person-years dimension, the proportion between the values is $11 / 10$. Thus, the one person is favored. In contrast, the proportion on the person-numbers dimension is $5 / 1$. On this dimension, the group is favored. The second proportion is equivalent to a number (5) which is greater than that yielded by the first proportion (1.1). So, according to this method, we should preserve the group of five persons.

This procedure has intuitively plausible implications in a variety of cases, but it does generate controversial results in others. For example, suppose we can save one person for three years or two persons for half a year each. The comparative proportion procedure prescribes the first option, but many people may prefer the second option.

What seems undeniable is that people value preservation along both dimensions, although perhaps they give somewhat more weight to the personnumbers dimension. A complete weighing scheme should take this into account. Health economists have begun to carry out empirical research on the relative weights that people place on life saving and life extension. ${ }^{29}$ Although many questions remain unclear, such studies can go some way in helping us to solve these difficult problems. Future studies may address people's moral judgments on respecting persons in the sorts of cases that we discussed.

\section{Conclusion}

It is important to recognize that in the cases we are examining - ones which involve the distribution of a scarce, life-saving resource - the demands of respect for persons might conflict with the demands of other moral principles. We attempted to lay the foundations for an account of respect for persons which is substantive and plausible and yet minimizes such conflicts. But some conflicts seem unavoidable. We should acknowledge them as a perhaps unfortunate but important feature of our moral landscape.

Among the situations in which the demands of respect for persons might conflict with those of other moral principles are ones in which we must choose between saving those whom we might call "lifespan disadvant-

${ }^{28}$ We thank Paul Menzel for this name. The procedure is described in more detail in Samuel J. Kerstein and Greg Bognar, "Complete Lives in the Balance," The American Journal of Bioethics 10 (2010), 37-45. A complication we set aside here is that a fully developed procedure would have to be sensitive to the uncertainty that characterizes many choices with regard to the number of persons preserved and the duration of their preservation.

${ }^{29}$ See, for example, Erik Nord, Cost-Value Analysis in Health Care: Making Sense Out of QALYs, Cambridge: Cambridge University Press, 1999. 
aged" persons and those who are free from such disadvantage. For example, we might have to choose between saving a person with a disability that reduces life expectancy and saving a person who does not have such a disability. Or we might have to choose between saving a person who belongs to a minority whose members, as a result of societal oppression and neglect, have a reduced lifespan and saving a person who belongs to a privileged group whose members have a normal lifespan. In both of these cases, the threetiered account would tell us to save the non-lifespan-disadvantaged person. But, again, some principle of distributive justice might imply that we really ought to save the disadvantaged person, for example, on the grounds that we ought to promote the welfare of the worst off, or at least of the worst off whose condition is not a result of her own poor but avoidable choices.

Our discussion has focused on the allocation of life-saving resources where saving the life of someone necessarily involves the death of someone else. Not all resource-allocation contexts have this structure, of course. For example, sometimes the lives of some must be weighed against a benefit for others whose lives are not at issue. Financial constraints might, for example, force us to choose between palliating a non-life-threatening, minor skin disease in thousands of people and performing intricate, life-saving organ transplantations for a few. The accounts we have examined here imply that respect for persons demands that we do the latter. They imply this because they attach a special value to capacities constitutive of personhood. The few will lose these capacities (die) if they do not receive transplants. But, by hypothesis, the skin disease suffered by the thousands neither threatens the existence of these capacities in them nor significantly hinders their exercise. Of course, benefit-maximizing principles may imply that we ought to treat the skin disease. We believe it is important to acknowledge such conflict. In the context of resource allocation, any substantive account of respect for persons is going to endorse actions that are rejected by moral principles that some find plausible.

We examined three accounts of respect for persons. We argued that two of these run into problems with regard to what we called different-age and different-number cases. We then outlined a third account that holds the promise of faring better in terms of its implications than its rivals, even though we acknowledged that a lot of further work needs to be done to fully develop and defend it.

Greg Bognar

New York University

Center for Bioethics

greg.bognar@nyu.edu
Samuel J. Kerstein

University of Maryland

Department of Philosophy

kerstein@umd.edu 